\title{
Measurement of the Earth Radiation Budget at the Top of the Atmosphere-A Review
}

\author{
Steven Dewitte * and Nicolas Clerbaux \\ Observations Division, Royal Meteorological Institute of Belgium, 1180 Brussels, Belgium; \\ nicolas.clerbaux@meteo.be \\ * Correspondence: Steven.Dewitte@meteo.be; Tel.: +32-2-3730624
}

Received: 25 September 2017; Accepted: 1 November 2017; Published: 7 November 2017

\begin{abstract}
The Earth Radiation Budget at the top of the atmosphere quantifies how the Earth gains energy from the Sun and loses energy to space. It is of fundamental importance for climate and climate change. In this paper, the current state-of-the-art of the satellite measurements of the Earth Radiation Budget is reviewed. Combining all available measurements, the most likely value of the Total Solar Irradiance at a solar minimum is $1362 \mathrm{~W} / \mathrm{m}^{2}$, the most likely Earth albedo is $29.8 \%$, and the most likely annual mean Outgoing Longwave Radiation is $238 \mathrm{~W} / \mathrm{m}^{2}$. We highlight the link between long-term changes of the Outgoing Longwave Radiation, the strengthening of El Nino in the period 1985-1997 and the strengthening of La Nina in the period 2000-2009.
\end{abstract}

Keywords: Earth Radiation Budget; Total Solar irradiance; Satellite remote sensing

\section{Introduction}

The Earth Radiation Budget (ERB) at the top of the atmosphere describes how the Earth gains energy from the sun, and loses energy to space through reflection of solar radiation and the emission of thermal radiation. The ERB is of fundamental importance for climate since:

(1) The global climate, as quantified e.g., by the global average temperature, is determined by this energy exchange.

(2) The solar insolation is stronger at the equator than at the poles, therefore the net ERB at the equator is positive, while it is negative at the poles. The equator to pole gradient of the ERB is the driver of the general circulation in the atmosphere and the oceans, which transports heat from the equator to the poles.

(3) In a climate at equilibrium the ERB terms are in balance. Climate change, as we are currently experiencing, is provoked by an ERB imbalance.

In this paper we review the efforts that have been made to measure the ERB from space, and we summarise the resultating state of our knowledge of the ERB. In Section 2 we review the measurements of the Total Solar Irradiance (TSI). In Section 3 we review the broadband space instruments used for the measurements of the outgoing terms of the ERB. In Section 4 we review the ERB instuments calibration results and the state of our knowledge of the ERB imbalance. In Section 5 we review the annual mean spatial distribution of the ERB. In Section 6 we review the interannual variability and long-term changes of the Outgoing Longwave Radiation (OLR). In Section 7 we discuss what has been achieved.

\section{Total Solar Irradiance}

The Total Solar Irradiance (TSI) quantifies the amount of solar energy that is received by the Earth. TSI is defined as the amount of solar power that reaches the Earth per unit surface perpendicular to the Sun-Earth direction at the mean Sun-Earth distance. 
The first TSI measurement from space was made with the Temperature Control Flux Monitor (TCFM) on Mariner 6 and 7 by Plamondon [1]. Continuous measurement of the TSI started with the Earth Radiation Budget (ERB) instrument on Nimbus 7 by Hickey et al. [2]. Continuous monitoring with an ageing corrected TSI instrument started with the Active Cavity Radiomer Irradiance Monitor (ACRIM) 1 instrument on the Solar Maximum Mission (SMM) by Willson et al. [3]. A summary of TSI space instruments is given in Table 1.

Table 1. Total Solar Irradiance space instruments. TCFM: Temperature Control Flux Monitor; ERB: Earth Radiation Budget; ACRIM: Active Cavity Radiomer Irradiance Monitor; SMM: Solar Maximum Mission; SOLCON: Solar Constant; ERBE: Earth Radiation Budget Experiment; ERBS: Earth Radiation Budget Satellite; NOAA: National Oceanic and Atmospheric Administration; UARS: Upper Atmosphere Research Satellite; ATLAS: Atmospheric Laboratory for Applications and Science; SOVA: Solar Variability; EURECA: European Retrievable Carrier; ISP: Solar Constant Gauge; DIARAD: Differential Absolute Radiometer; VIRGO: Variability of Irradiance and Gravity Oscillations; SOHO: Solar and Heliospheric Observatory; PMO: Physikalisches und Meteorologisches Observatorium; TIM: Total Irradiance Monitoring; SORCE: Solar Radiation and Climate Experiment; SOVIM: Solar Variability Irradiance Monitor; SIM: Solar Irradiance Monitor; FY: Feng Yung; PREMOS: Precision Monitor Sensor; TCTE: Total Solar Irradiance Calibration Transfer Experiment.

\begin{tabular}{lll}
\hline Period & Instrument & References \\
\hline 1969 & TCFM on Mariner 6 and 7 & {$[1]$} \\
1975 & ERB on Nimbus 6 & {$[4]$} \\
1978 & ERB on Nimbus 7 & {$[2]$} \\
$1980-1989$ & ACRIM 1 on SMM & {$[3]$} \\
1983 & Solcon 1 on Spacelab 1 & {$[5]$} \\
$1984-2003$ & ERBE on ERBS & {$[6]$} \\
$1985-1989$ & ERBE on NOAA-9 & {$[6]$} \\
$1991-2001$ & ACRIM 2 on UARS & {$[7]$} \\
1992 & Solcon 2 on Atlas 1 & {$[8]$} \\
$1992-1993$ & Sova 1 on Eureca & {$[8]$} \\
$1992-1993$ & Sova 2 on Eureca & {$[9]$} \\
1994 & ISP-2 on Meteor-3 7 & {$[10]$} \\
$1996-$ present & DIARAD/VIRGO on SOHO & {$[11]$} \\
1996-present & PMO06V-A/VIRGO on SOHO & {$[12]$} \\
$2000-2014$ & ACRIM 3 on ACRIMSAT & {$[13]$} \\
$2003-$ present & TIM on SORCE & {$[14]$} \\
2008 & DIARAD/SOVIM on the ISS & {$[15]$} \\
$2008-2015$ & SIM on FY3A & {$[16]$} \\
$2010-2014$ & Sova-Picard & {$[17]$} \\
$2010-2014$ & Premos on Picard & {$[18]$} \\
$2011-p r e s e n t$ & SIM on FY3B & {$[16]$} \\
$2013-$ present & TIM on TCTE & {$[19]$} \\
2013-present & SIM on FY3C & {$[20]$} \\
\hline
\end{tabular}

The instruments used for the TSI measurement are electrical substitution cavity radiometers. Their core detector consists of a blackened cavity in which nearly all incident radiation flowing through a precision aperture is absorbed. The thermal effect of the absorbed optical power is measured by comparison with the thermal effect of known electrical power.

A TSI radiometer ages by exposure to solar UV radiation. For ageing correction, a backup channel is used, for which the total solar UV exposure is kept low such that the ageing of the backup channel is negligible.

Relative variations of the TSI in phase with the 11-year solar cycle of the order of $1 \mathrm{~W} / \mathrm{m}^{2}$ are now well established, as summarised by Dewitte and Nevens [21]. Apart from these true TSI variations, differences in the absolute level above $1 \mathrm{~W} / \mathrm{m}^{2}$ are measured by different instruments indicating limitations of the absolute accuracy. 
As the Sun is nearly a point source, TSI radiometers use a view-limiting mechanism to eliminate the entrance of all except direct solar radiation into the cavity.

Classical radiometers place a large view-limiting aperture in front of a small precision aperture. In this geometry, scattering and diffraction around the edges of the view-limiting aperture increase the amount of solar power flowing through the precision aperture. When this effect is underestimated it may lead to a too-high measurement of the TSI.

The Total Irradiance Monitoring (TIM) radiometers use an alternative geometry where the small precision aperture is put in front of the larger view-limiting aperture. In this geometry, scattering and diffraction around the edges of the precision aperture decrease the amount of solar power flowing through the view limiting aperture. When this effect is underestimated it may lead to a too-low measurement of the TSI.

Table 2 summarises the equivalent TSI at a solar minimum measured by three independent instruments: TIM on the Solar Radiation and Climate Experiment (SORCE) in 2003, the Differential Absolute Radiometer (DIARAD) as part of the Solar Variability Irradiance Monitor (SOVIM) in 2008 and TIM on the Total Solar Irradiance Transfer Experiment (TCTE) in 2013. We consider TIM/TCTE as more reliable than TIM/SORCE, since TIM/TCTE went through additional pre-flight characterisations as compared to TIM/SORCE. A TSI level at a solar minimum of $1362+/-0.9 \mathrm{~W} / \mathrm{m}^{2}$ can be derived from the combination of DIARAD/SOVIM and TIM/TCTE.

Figure 1 shows the composite TSI obtained following the methodology of Dewitte and Nevens [21], adopting the mean level of DIARAD/SOVIM and TIM/TCTE, and with extension prior to 1984 of the TSI measurements by the Satire regression model from Ball et al. [22] based on the Kitt Peak ground magnetograms.

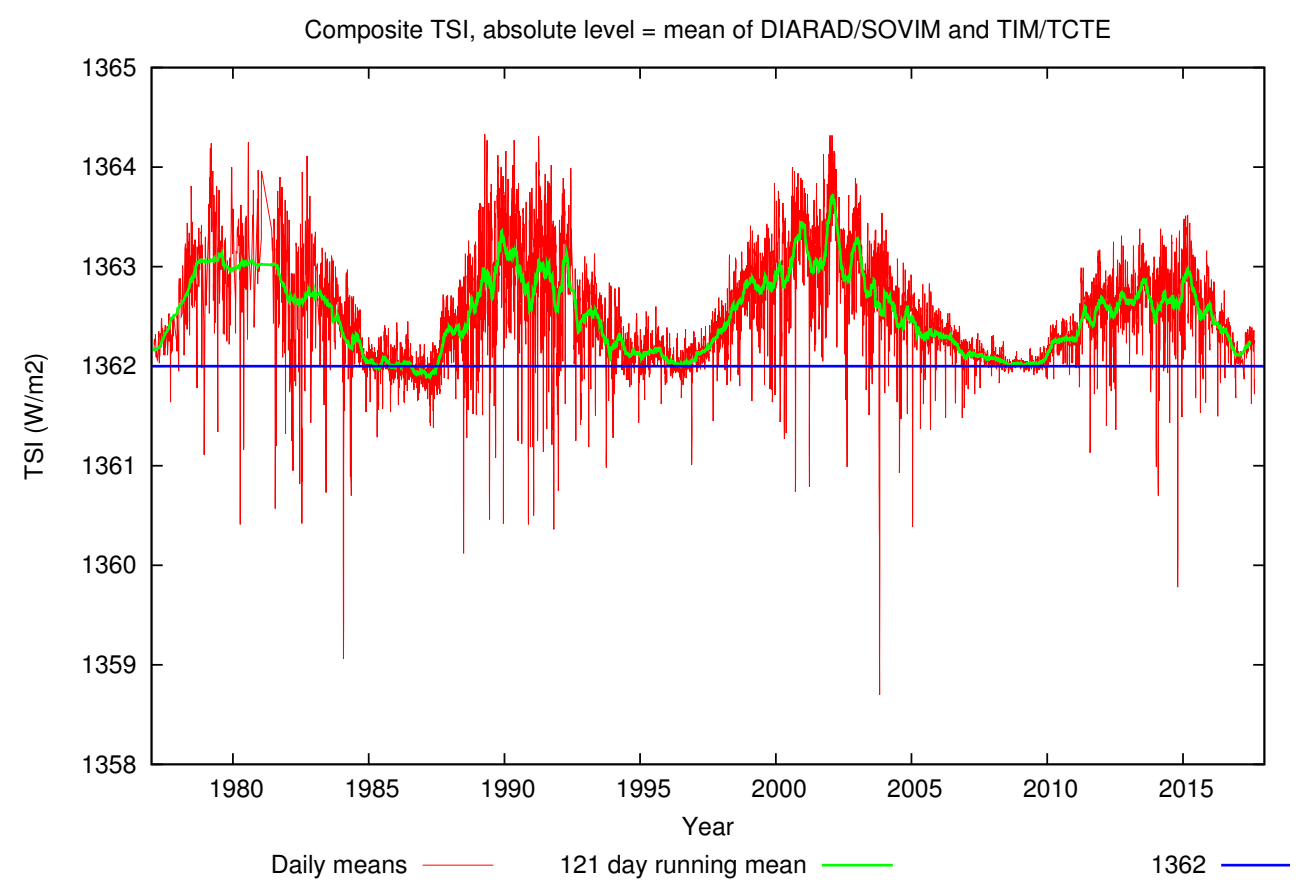

Figure 1. Composite Total Solar Irradiance (TSI) at the mean absolute level of DIARAD/SOVIM and TIM/TCTE. 
Table 2. Alternative TSI levels at solar minimum. TCTE: Total Solar Irradiance Transfer Experiment.

\begin{tabular}{|c|c|c|}
\hline Instrument & Year Launched & TSI Level Solar Minimum (W/m²) \\
\hline TIM/SORCE & 2003 & 1360.5 \\
\hline DIARAD/SOVIM & 2008 & 1362.9 \\
\hline TIM/TCTE & 2013 & 1361.2 \\
\hline Mean DS TT & & $1362.0+/-0.9$ \\
\hline
\end{tabular}

\section{Earth Radiation Budget Instruments}

Measurement of the ERB from space started with the measurements of Explorer VI and VII in 1969, as reported by Vonder Haar and Raschke [23]. Early measurements of the ERB have been reviewed by House et al. [24]. Measurements with dedicated broadband instruments started on Nimbus 6 in 1975 by Jacobowitz et al. [25]. Nimbus 6 contained two types of instruments: a Non-Scanning (NS) or Wide Field Of View (WFOV) instrument which measures the radiation of the earth from limb to limb, and a scanning Narrow Field Of View (NFOV) instrument, which measures the radiation from the Earth with higher resolution.

Table 3 lists the non-scanning ERB instruments flown in space.

Table 3. Non-Scanning Broadband Earth Radiation Budget space instruments. IKOR: Short-wave outgoing radiation monitor; ERM: Earth Radiation Monitor; RAVAN: Radiometer Assessment using Vertically Aligned Nanotubes.

\begin{tabular}{llc}
\hline Period & Instrument & References \\
\hline $1975-1978$ & ERB on Nimbus 6 & {$[25]$} \\
$1978-1987$ & ERB on Nimbus 7 & {$[25]$} \\
$1984-1999$ & ERBE on ERBS & {$[26]$} \\
$1985-1990$ & ERBE on NOAA 9 & {$[26]$} \\
$1986-1994$ & ERBE on NOAA 10 & {$[26]$} \\
1994 & IKOR (SW only) on Meteor-3 7 & {$[27]$} \\
1998 & IKOR (SW only) on Resurs-1 & {$[27]$} \\
$2008-2011$ & ERM NS on FY3A & {$[28]$} \\
$2009-2014$ & IKOR-M (SW only) on Meteor-M 1 & {$[29]$} \\
2011 & ERM NS on FY3B & {$[28]$} \\
$2013-$ present & ERM NS on FY3C & {$[28]$} \\
$2014-$ present & IKOR-M (SW only) on Meteor-M 2 & {$[30]$} \\
2016 & RAVAN & {$[31]$} \\
\hline
\end{tabular}

Non-Scanning ERB instruments have a similar design to the TSI radiometers, e.g., the Earth Radiation Budget Experiment (ERBE) NS ERB instruments are a derivative of the ACRIM TSI radiometer (see Barkstrom and Smith [26]). The main difference is in the opening angle which is $120^{\circ}$ for a WFOV radiometer while it is a few degrees for a TSI radiometer. WFOV ERB radiometers measure the true radiative flux at satellite altitude. The reflected solar radiation with wavelengths shorter than 4 microns is also called ShortWave (SW) radiation. The emitted thermal radiation with wavelengths longer than 4 microns is also called LongWave (LW) radiation. A black radiometer without front window measures the total (TOT) radiation, which is the sum of the SW and the LW radiation. A SW radiometer is obtained by putting a quartz window in front of a TOT radiometer. LW radiation can be measured as TOT minus SW.

The size of the Field Of View (FOV) of a WFOV radiometer is several thousand kilometers, which prohibits, for example, the discrimination between clear sky and cloudy scenes. Higher spatial resolution is obtained with the NFOV instruments, with a spatial resolution of the order of 10 to $100 \mathrm{~km}$. In order to capture the Earth's radiation at all viewing zenith angles, these radiometers are scanning.

Table 4 lists the scanning ERB NFOV instruments flown in space on Low Earth Orbit satellites. 
Table 4. Scanning Broadband Earth Radiation Budget space instruments on Low Earth Orbit satellites. CERES: Clouds and the Earth's Radiant Energy System; ScaRaB: Scanning Radiometer for Radiation Balance; TRMM: Tropical Rainfall Measuring Mission; NPP: National Polar-orbiting Operational Environmental Satellite System Preparatory Project.

\begin{tabular}{llc}
\hline Period & Instrument & References \\
\hline July-August 1975 & ERB on Nimbus 6 & {$[25]$} \\
$1978-1980$ & ERB on Nimbus 7 & {$[25]$} \\
$1984-1989$ & ERBE on ERBS & {$[26]$} \\
$1985-1987$ & ERBE on NOAA 9 & {$[26]$} \\
$1986-1989$ & ERBE on NOAA 10 & {$[26]$} \\
$1994-1995$ & ScaRaB-1 on Meteor-3 7 & {$[32]$} \\
$1997-1998$ & CERES on TRMM & {$[33]$} \\
$1998-1999$ & ScaRaB-2 on Resurs-1 & {$[34]$} \\
$2000-$ present & CERES FM1 on Terra & {$[33]$} \\
$2000-$ present & CERES FM2 on Terra & {$[33]$} \\
$2003-$ present & CERES FM3 on Aqua & {$[33]$} \\
$2003-$ present & CERES FM4 on Aqua & {$[33]$} \\
$2008-2010$ & ERM on FY3A & {$[28]$} \\
$2011-$ present & ScaRaB-3 on Megha-Tropiques & {$[35]$} \\
$2011-$ present & CERES FM5 on Suomi NPP & {$[33]$} \\
2011 & ERM on FY3B & {$[28]$} \\
$2013-$ present & ERM on FY3C & {$[28]$} \\
\hline
\end{tabular}

A NFOV instrument does not measure a flux but a radiance. To convert the radiance to a flux estimate, an Angular Dependency Model (ADM) is needed. The ADM's used for ERBE were derived from the Nimbus 7 Scanner instrument by Suttles et al. [36,37]. The Clouds and the Earth's Radiant Energy System (CERES) instruments have a rotating azimuth capability, which has been used to derive improved ADM's by Loeb et al. [38].

A polar satellite provides global spatial sampling, but has limited temporal sampling with only one daytime and one nighttime measurement per day for all locations but the polar regions. For a proper sampling of the diurnal cycle of the ERB, the Geostationary Earth Radiation Budget (GERB) instruments described by Harries et al. [39] are flown on the Meteosat Second Generation (MSG) satellites described by Schmetz et al. [40].

Table 5 lists the GERB instruments flown in space.

Table 5. Broadband Earth Radiation Budget space instruments on geostationary satellites. GERB: Geostationary Earth Radiation Budget; MSG: Meteosat Second Generation.

\begin{tabular}{lll}
\hline Period & Instrument & References \\
\hline 2003-present & GERB2 on MSG1 & {$[39,41]$} \\
2007-2012 & GERB1 on MSG2 & {$[39,41]$} \\
2012-present & GERB3 on MSG3 & {$[39,41]$} \\
2015 & GERB4 on MSG4 & {$[39,41]$} \\
\hline
\end{tabular}

Nominally, the MSG satellites are located at a longitude close to $0^{\circ}$. Since October 2016, the oldest of the MSG satllites, MSG-1 also called Meteosat- 8 , has been relocated to $41.5^{\circ}$ east longitude.

\section{Calibration}

ERB instruments are calibrated on-ground with absolute calibration sources; typically a blackbody is used as a LW calibration source, and a lamp with an irradiance known relative to a primary standard is used as a SW calibration source. In flight, the stability of the calibration is checked or maintained using relative calibration sources. 
When two ERB instruments are overlapping in time, their absolute calibration can be checked by in-flight intercomparsion of these two instruments. A compilation of the results of such intercomparisons up to 2006 was made by Smith et al. [42]. We have completed this compilation with the results of Clerbaux et al. for Gerb-2 [43], and Gerb-1 [44], and Chomette et al. [45] for the Scanning Radiometer for Radiation Balance (ScaRaB) 3. Table 6 summarises the calibration biases of the different ERB instruments compared to the Earth Radiation Budget Satellite (ERBS) Scanner.

Table 6. Bias of instruments relative to the Earth Radiation Budget Satellite (ERBS) Scanner.

\begin{tabular}{ccc}
\hline & SW (\%) & LW (\%) \\
\hline Gerb2/MSG1 & 5.4 & -1.7 \\
ScaRaB3 & 2.9 & -1.5 \\
ERBS NS & 2.3 & -1.5 \\
ScaRaB2 & 2.2 & -0.9 \\
ScaRaB1 & 1.9 & -0.7 \\
CERES FM1 & 0.8 & -0.6 \\
CERES PFM & 0.8 & -0.1 \\
CERES FM2 & 0.7 & -0.7 \\
CERES FM4 & 0.5 & -0.3 \\
CERES FM4 & 0.5 & -0.4 \\
Gerb1/MSG2 & 0.4 & -1.3 \\
\hline
\end{tabular}

Combining the ERB intercomparison results from Table 6 with the CERES data from Loeb et al. [46], for the reference period from March 2000 to February 2005, we get a Reflected Solar Flux (RSF) of $99.6+/-2.7 \mathrm{~W} / \mathrm{m}^{2}$ and an OLR of $236.5+/-2.0 \mathrm{~W} / \mathrm{m}^{2}$. The given uncertainties are absolute uncertainties; they are based on the observed instrument calibration differences of Table 6 . Following Section 2, the TSI is $1362.9+/-0.9 \mathrm{~W} / \mathrm{m}^{2}$. The corresponding incoming solar flux is $340.4+/-0.2 \mathrm{~W} / \mathrm{m}^{2}$. The observed Earth's Energy Imbalance (EEI) between incoming solar and outgoing terrestrial flux is then $4.3+/-4.9 \mathrm{~W} / \mathrm{m}^{2}$.

An independent estimate of the EEI derived from Ocean Heat Content (OHC) of $0.9+/-0.3 \mathrm{~W} / \mathrm{m}^{2}$ is given in [47]. The indirect estimate of the EEI from OHC is thus more precise than the direct radiative measurement. Following a method similar to Loeb et al. [46], we can adjust the OLR and RSF within their observed uncertainty to make them consistent with the OHC EEI. We assume the uncertainties on the RSF and the OLR are independent and have Gaussian distributions. Then the most likely value of the RSF is $101.6 \mathrm{~W} / \mathrm{m}^{2}$ and the most likely value of the OLR is $238.0 \mathrm{~W} / \mathrm{m}^{2}$. The corresponding Earth albedo is $29.8 \%$.

Table 7 lists the adjustment factors by which the readings of an individual instrument have to be multiplied in order to reproduce the most likely RSF or OLR values.

Table 7. Adjustment factors of instruments. RSF: Reflected Solar Flux; OLR: Outgoing Longwave Radiation.

\begin{tabular}{ccc}
\hline & RSF & OLR \\
\hline Gerb2/MSG1 & 0.993 & 1.015 \\
ScaRaB3 & 1.017 & 1.013 \\
ERBS NS & 1.024 & 1.013 \\
ScaRaB2 & 1.025 & 1.007 \\
ScaRaB1 & 1.028 & 1.005 \\
CERES FM1 & 1.038 & 1.003 \\
CERES PFM & 1.039 & 0.999 \\
CERES FM2 & 1.040 & 1.005 \\
CERES FM4 & 1.042 & 1.001 \\
CERES FM4 & 1.042 & 1.002 \\
Gerb1/MSG2 & 1.043 & 1.010 \\
ERBS Scanner & 1.047 & 0.998 \\
\hline
\end{tabular}




\section{Climatology}

In this section we briefly discuss the multi-annual mean global spatial distributions of the ERB components.

Figure 2 shows the climatology of the net radiation—defined as the absorbed solar radiation minus the OLR — obtained from the CERES Energy Balanced And Filled (EBAF) product—obtained following the methodology of Loeb et al. [46] — from February 2000 to March 2010. Its spatial structure shows an equator to pole gradient, which is caused by the gradient of the incoming solar radiation. This equator to pole gradient is itself the driver of the general circulation in the atmosphere and in the oceans as described by Trenberth and Carron [48].

Figure 3 shows the climatology of the total outgoing radiation-defined as the OLR plus the RSF-from the CERES EBAF product for the same period.

It shows a strong radiative cooling for the marine stratocumulus regions west of the coasts of Namibia, Peru, California, and to a lesser extent west of Australia. The presence of these marine stratocumulus is provoked by the subsidence in the Hadley and Walker circulations, and their radiative cooling helps to maintain this circulation. They also play an important role in the so-called cloud feedback as described by Stephens [49].

Figure 3 also shows a strong cooling over desert, particularly the Sahara and the Arabian desert. The strong cooling is caused by the relatively high surface albedo and the prevailence of clear sky conditions. It influences the local circulation as described by Charney [50], pumping energy out of the circulation and radiating it to space as described by Blake et al. [51].

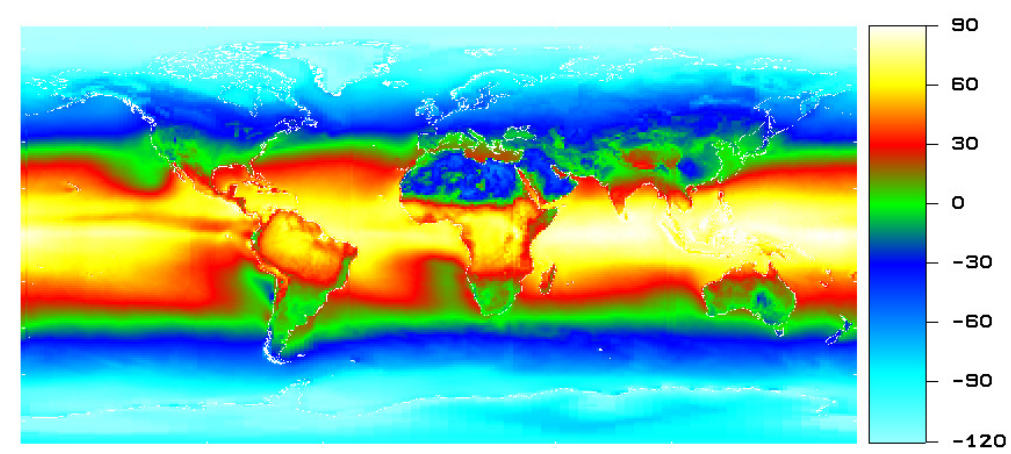

Figure 2. The 10-year mean CERES Energy Balanced And Filled (EBAF) Net Incoming Flux.

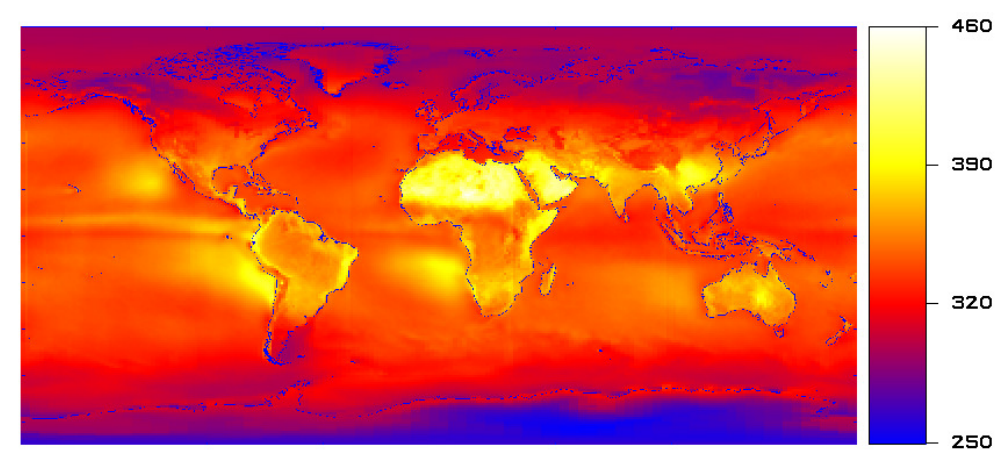

Figure 3. The 10-year mean CERES EBAF Total Outgoing Flux.

Figures 4 and 5 shows the CERES EBAF climatologies of the RSF and the OLR, respectively. High reflection by thick clouds and low emission by cold cloud tops is seen for the tropical convective regions and for the midlatitude regions with frontal cloudiness. For most cloud regions there is 
a compensation between RSF cooling and OLR heating. The exceptions are the marine stratocumulus clouds for which the RSF cooling is not compensated by OLR heating.

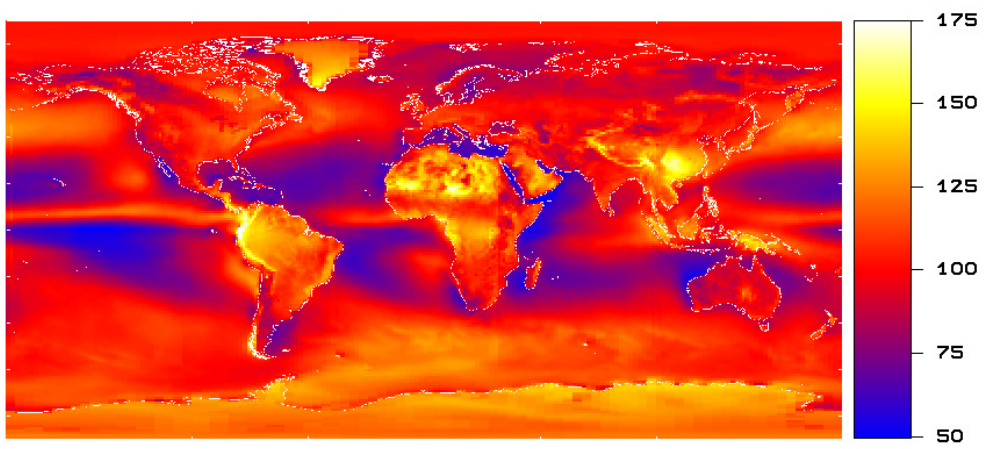

Figure 4. The 10-year mean CERES EBAF Reflected Solar Flux.

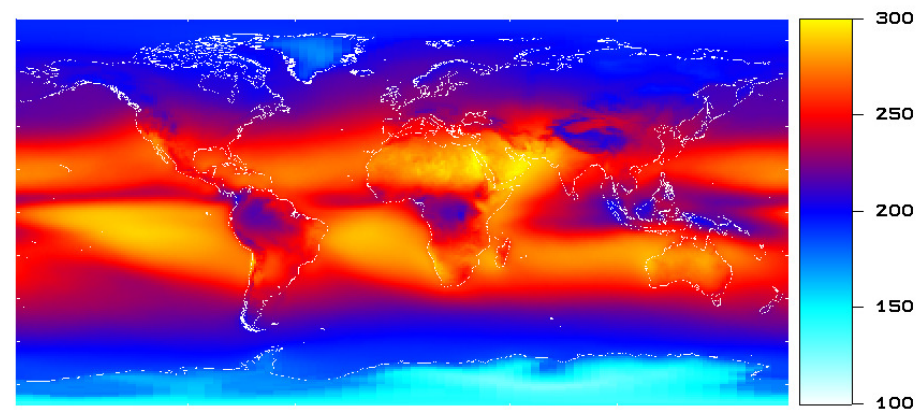

Figure 5. The 10-year mean CERES EBAF Outgoing Longwave Radiation.

Figure 6 shows the climatology of the OLR from the ERBS WFOV between $+/-57$ degrees from 1985 to 1997. Although it clearly has a lower spatial resolution than CERES - see Figure 5-it shows similar features.

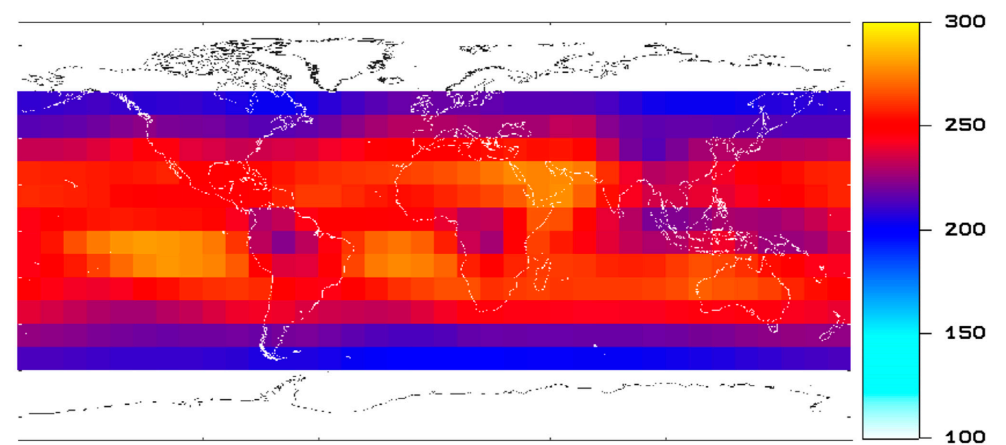

Figure 6. The 13-year mean ERBS Wide Field Of View (WFOV) Outgoing Longwave Radiation.

\section{Interannual Variability and Long-Term Changes}

Tropical convection is caused by the diurnal wave of solar heating travelling around the Earth from east to west. Land masses heat up more quickly than oceans, and therefore tropical convection occurs preferentially over land. Two stable convection maxima - visible as OLR minima in Figure 5-exist over the land masses of South America and Central Africa. A third convection maximum exists around Indonesia, with a western branch towards the Indian Ocean, and an eastern branch towards the Pacific. Since not much land is present in this area, the 'Indonesian' convection maximum is 
unstable; this instability gives rise to the well known El Nino/La Nina variability as described by Mc Phaden et al. [52], which is the main mode of interannual climate variability.

Figure 7 shows the variability of the OLR between La Nina years and El Nino years. The mean CERES EBAF OLR for the El Nino years 2002, 2003, 2004, 2006, and 2009 was subtracted from the mean OLR for the La Nina years 2000, 2001, 2005, 2007, and 2008. El Nino and La Nina years were identified using the Multivariate El Nino index by Wolter and Timlin [53].

During La Nina the eastern and the western branches of the 'Indonesian' convection maximum move towards each other; as a result the OLR around Indonesia decreases as shown by the deep minimum around Indonesia in Figure 7. The high precipitation corresponding to low OLR increases, causing flooding in Indonesia, South-East Asia, and Australia. Through the general Walker circulation there is a 'communication' between the three convection maxima, resulting in a teleconnected pattern of variation over the entire tropics, visible in Figure 7. e.g., during La Nina there is an increase in OLR—and corresponding drought—over the Southern US.

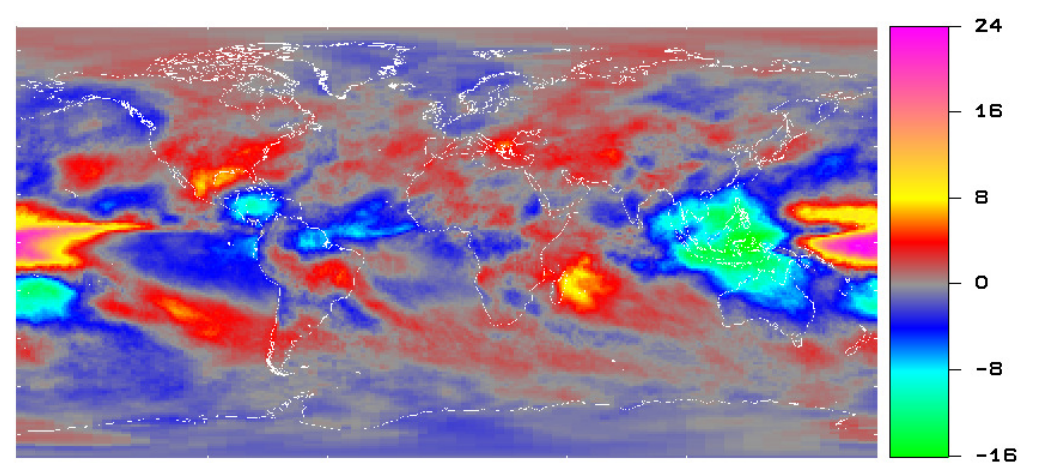

Figure 7. CERES EBAF Outgoing Longwave Radiation variability between La Nina years and El Nino years.

Figure 8 shows the long-term change of the OLR over the period 2000-2009. The mean CERES EBAF OLR for the period 2000-2004 was subtracted from the mean OLR for the period 2005-2009.

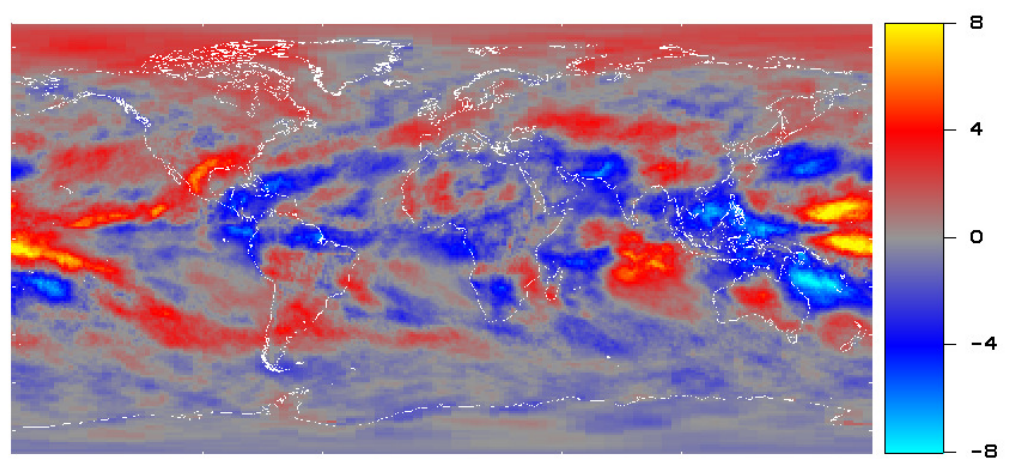

Figure 8. CERES EBAF Outgoing Longwave Radiation long-term change from 2000-2004 to 2005-2009.

The spatial pattern of the 2000-2009 long-term change as shown in Figure 8 is similar to the variation from El Nino to La Nina conditions shwon in Figure 7. Thus, during 2000-2009 there was a general strengthening of La Nina conditions.

Figure 9 shows the long-term change of the OLR over the earlier period 1985-1997. The mean ERBS WFOV OLR for the period 1985-1990 was subtracted from the mean OLR for the period 1991-1997.

Figure 10 shows the variability of the OLR between El Nino years and La Nina years as seen by the ERBS WFOV instrument. The mean ERBS WFOV OLR for the La Nina years 1985, 1988, 
1989, and 1996 was subtracted from the mean OLR for the El Nino years 1987, 1991, 1992, and 1997. El Nino and La Nina years were identified using the Multivariate El Nino index by Wolter and Timlin [53].

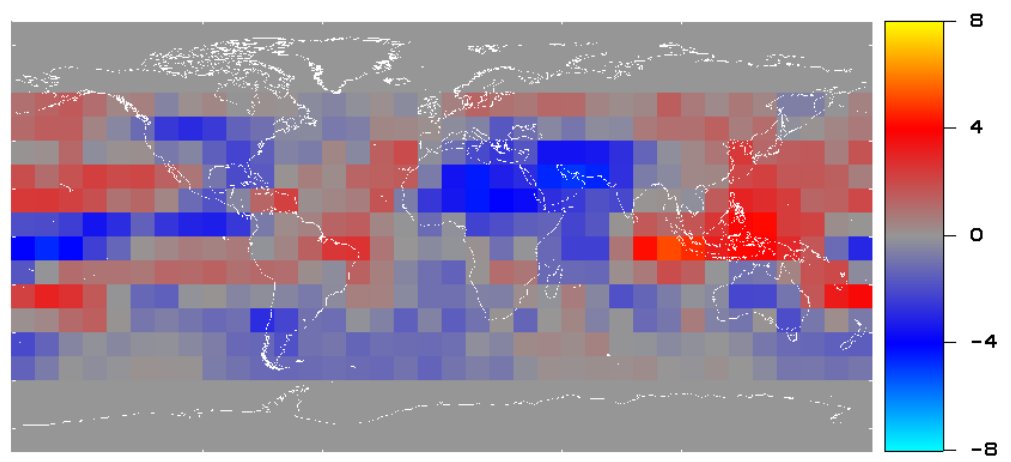

Figure 9. ERBS WFOV Outgoing Longwave Radiation long-term change from 1985-1990 to 1991-1997.

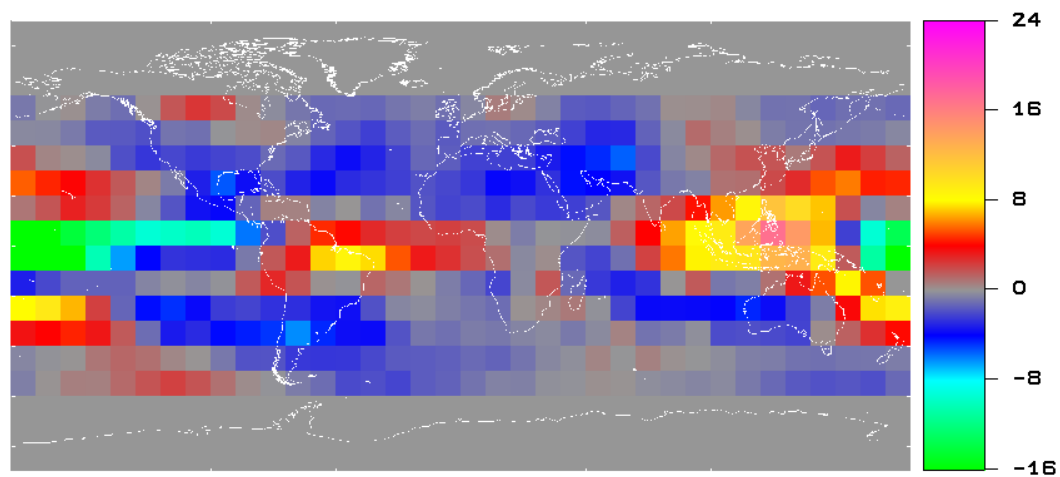

Figure 10. ERBS WFOV Outgoing Longwave Radiation variability between El Nino years and La Nina years.

The spatial pattern of the 1985-1997 long-term change as shown in Figure 9 is similar to the variation from La Nina to El Nino conditions shown in Figure 10. Thus, during 1985-1997 there was a general strengthening of El Nino conditions.

The period of El Nino strengthening from 1985-1997 corresponded to a period of strong global temperature rise as described by Hansen et al. [54], but also to a period of increase of surface solar irradiance also called global brightening as described by Wild [55] and Dewitte et al. [56].

The period of La Nina strengthening from 2000-2009 corresponded to a period of global temperature stagnation, but also to a period of increase of decreasing surface solar irradiance due to increasing air pollution over South East Asia as described by Dewitte et al. [56].

It should be noted that a period of temperature stagnation does not mean absence of heat uptake by the Earth. Following Allan et al. [57] the EEI in the 2000-2012 period was $0.62+/-0.43 \mathrm{~W} / \mathrm{m}^{2}$, while it was $0.34+/-0.67 \mathrm{~W} / \mathrm{m}^{2}$ for the $1985-1999$ period. It seems that during the period of temperature stagnation the energy uptake by the Earth was actually higher than during the period of strong temperature rise.

\section{Discussion}

Due to its fundamental importance for climate and climate change, the long-lasting efforts to measure the ERB including the TSI from space are fully justified. These measurements are demanding both in terms of stability and absolute accuracy. 
TSI measurements from space have been made since 1969. TSI measurements with good stability have been available since 1984. They reveal a variation of the TSI in phase with the 11-year sunspot cycle, with an amplitude of the order of $1 \mathrm{~W} / \mathrm{m}^{2}$. The currently-ending solar cycle 24 has a low amplitude compared to the preceding ones.

The TIM TSI instruments have a different viewing geometry as compared to the classical TSI instruments, which results in a lower absolute value of the measured TSI. Reconciling the classical DIARAD/SOVIM and the new TIM/TCTE instrument, the TSI level at solar minimum is estimated to be $1362.0+/-0.9 \mathrm{~W} / \mathrm{m}^{2}$.

The ERB measurements have sufficient stability to track the temporal variability of the EEI driving climate change, but they can not measure its absolute value with sufficient accuracy. Combining the ERB measurements with independent estimates of the EEI from OHC, we obtain the most likely values of the OLR of $238.0 \mathrm{~W} / \mathrm{m}^{2}$ and of the RSF of $101.6 \mathrm{~W} / \mathrm{m}^{2}$-corresponding to an albedo of $29.8 \%$-for the period 2000-2005.

Long-term changes of the OLR measured by the ERBS WFOV instrument reveal a general strengthening of El Nino conditions for the period 1985-1997, while the CERES measurements reveal an opposite strengthening of La Nina conditions for the period 2000-2009. There are possible links with surface solar irradiance brightening/dimming, temperature rise/stagnation and EEI level. Understanding these links is of fundamental importance for understanding climate change, and therefore deserves further study.

Acknowledgments: This review was exectuted in the context of the Virgo, Gerb and Climate SAF projects, with funding from the Belgian Science Policy Office Belspo and the European Meteorological Satellite organisation Eumetsat.

Conflicts of Interest: The authors declare no conflict of interest.

\section{References}

1. Plamondon, J. TCFM solar observations on Mariner 6. JPL Space Progr. Summ. 1969, 37-69, 162.

2. Hickey, J.; Stowe, L.; Jacobowitz, H.; Pellegrino, P.; Machhoff, R.; House, F.; Haar, T.V. Initial solar irradiance determinations from nimbus 7 cavity radiometer measurements. Science 1980, 208, 281-283.

3. Willson, R.; Gulkis, S.; Janssen, M.; Hudson, H.; Chapman, G. Observations of Solar Irradiance Variability. Science 1980, 211, 700-702.

4. Hickey, J.; Griffin, F.; Hilleary, D.; Howell, H. Extraterrestrial Solar Irradiance Measurements From the Nimbus 6 Satellite. In Sharing the Sun: Solar Technology in the Seventies, Proceedings of the Joint Conference, Winnipeg, Canada, 15-20 August 1976; American Section of the International Solar Energy Society: Boulder, CO, USA, 1976; pp. 329-337.

5. Crommelynck, D.; Brusa, R.; Domingo, V. Results of the solar constant experiment onboard Spacelab-1. Solar Phys. 1987, 107, 1-9.

6. ERBE Science Team. First data from the Earth Radiation Budget Experiment. BAMS 1986, 67, 818-824.

7. Willson, R. Irradiance observations of SMM, Spacelab-1, UARS and ATLAS experiments. In The Sun as a Variable Star: Solar and Stellar Irradiance Variations, Proceedings of the IAU Colloquium No. 143, Boulder, CO, USA, 20-25 June 1993; Cambridge University Press: Cambridge, UK, 1994; Volume 143, pp. 54-62.

8. Crommelynck, D.; Domingo, V.; Fichot, A.; Lee, R. Total Solar Irradiance observations from the EURECA and ATLAS experiments. In The Sun as a Variable Star, Proceedings of the IAU Colloquium No. 143, Boulder, CO, USA, 20-25 June 1993; Cambridge University Press: Cambridge, UK, 1994; Volume 143, pp. 63-69.

9. Romero, J.; Wherli, C.; Froehlich, C. Solar Total Irradiance variability from Sova 2 on board Eureca. Sol. Phys. 1994, 152, 23-29.

10. Sklyarov, Y.; Brichkov, Y.; Vorobev, V.; Kotuma, A. The satellite borne instrument Solar-Constant Gauge. Astron. Lett. 1996, 22, 318-320.

11. Dewitte, S.; Crommelynck, D.; Joukoff, A. Total Solar Irradiance observations from DIARAD/VIRGO. J. Geophys. Res. Space Phys. 2004, 109, A02102. 
12. Froehlich, C.; Crommelynck, D.; Wherli, C.; Anklin, M.; Dewitte, S.; Fichot, A.; Finsterle, W.; Jimenez, A.; Chevalier, A.; Roth, H.-J. In-flight performance of the VIRGO solar irradiance instrument on SOHO. Solar Phys. 1997, 175, 267-286.

13. Willson, R.; Mordvinov, A. Secular total solar irradiance trend during solar cycles 21-23. GRL 2003, 30, 1199.

14. Kopp, G.; Lawrence, G.; Rottman, G. The Total Irradiance Monitor (TIM): Science results. Solar Phys. 2005, 230, 129-139.

15. Mekaoui, S.; Dewitte, S.; Conscience, C.; Chevalier, A. Total solar irradiance absolute level from DIARAD/SOVIM on the International Space Station. Adv. Space Res. 2010, 45, 1393-1406.

16. Fang, W.; Wang, H.; Li, H.; Wang, Y. Total Solar Irradiance Monitor for Chinese FY-3A and FY-3B Satellites: Instrument Design. Solar Phys. 2014, 289, 4711-4726.

17. Dewitte, S.; Janssen, E.; Mekaoui, S. Science results from the Sova-Picard total solar irradiance instrument. AIP Conf. Proc. 2012, 1531, 688.

18. Schmutz, W.; Fehlmann, A.; Finsterle, W.; Kopp, G.; Thuillier, G. Total solar irradiance measurements with PREMOS/Picard. AIP Conf. Proc. 2012, 1531, 624.

19. Kopp, G. Solar Variability Magnitudes and Timescales. J. Space Weather Space Clim. 2016, 6, A30. doi:10.1051/swsc/2016025.

20. Wang, H.; Wang, Y.; Ye, X.; Yang, D.; Wang, K.; Li, H.; Fang, W. Instrument Description: The Total Solar Irradiance Monitor on the FY-3C Satellite, an Instrument with a Pointing System. Solar Phys. 2017, $289,8$.

21. Dewitte, S.; Nevens, S. The Total Solar Irradiance Climate Data Record. Astrophys. J. 2016, 830, 5.

22. Ball, W.; Unruh, Y.; Krivova, N.; Solanki, S.; Wenzler, T.; Mortlock, D.; Jaffe, A. Reconstruction of total solar irradiance 1974-2009. Astron. Astrophys. 2012, 541. doi:10.1051/0004-6361/201118702.

23. Haar, T.V.; Raschke, E. Measurements of the Energy Exchange Between Earth and Space From Satellites during the 1960's; Colorado State University: Fort Collins, CO, USA,1972; Volume 184.

24. House, F.; Gruber, A.; Hunt, G.; Mecherikunnel, A. History of satellite missions and measurements of the earth radiation budget (1957-1984). Rev. Geophys. 1986, 24, 357-377.

25. Jacobowitz, H.; Soule, H.; Kyle, H.; House, F. The Earth Radiation Budget (ERB) experiment: An overview. J. Geophys. Res. 1984, 89, 5021-5038.

26. Barkstrom, B.; Smith, G. The Earth Radiation Budget Experiment: science and implementation. Rev. Geophys. 1986, 24, 379-390.

27. Sklyarov, Y.; Brichkov, Y.; Vorobyov, V.; Kotuma, A.; Fomina, N. Radiometric measurements from Russian satellites Meteor-3 7 and Resurs-1. Mapp. Sci. Remote Sens. 2000, 37, 73-75.

28. Qiu, H.; Qi, J.; Zhang, P.; Zhang, Y.; Hu, L. The introduction of Earth Radiation Budget measurements on Chinese FY-3 series satellites. In Proceedings of the Radiat. Budget Workshop, Reading, UK, 18-21 October 2016.

29. Sklyarov, Y.; Vorobyov, V.; Kotuma, A.; Chervykov, M.; Feigin, V. The measurement of radiation balance from Meteor-M satellite: The IKOR-M radiometer. Curr. Probl. Remote Sens. Earth 2012, 9, 173-180.

30. Cherviakov, M. Variability of Earth's Radiation Budget Components during 2009-2015 from IKOR-M Data. In Proceedings of the EGU General Assembly Conference, Vienna Austria, 17-22 April 2016.

31. Swartz, W.; Dyrud, L.; Lorentz, S.; Wu, D.; Wiscombe, W.; Papadakis, S. The RAVAN cubesat mission: Progress toward a new measurement of earth outgoing radiation. Presented at Sun-Climate Symposium, Savannah, GA, USA, 10-13 November 2015.

32. Kandel, R.; Viollier, M.; Raberanto, P.; Duvel, J.-P.; Pakhomov, L.; Golovko, V.; Trischenko, A.; Mueller, J.; Raschke, E.; Stuhlmann, R. The ScaRaB earth radiation budget dataset. Bull. Am. Meteorol. Soc. 1998, 79, 765-783.

33. Wielicki, B.; Barkstrom, B.; Harrison, E.; Lee, R.; Smith, G.; Cooper, J. Clouds and the Earth's Radiant Energy System (CERES): An earth observing experiment. Bull. Am. Meteorol. Soc. 1996, 77, 853-868.

34. Duvel, J.-P.; Viollier, M.; Raberanto, P.; Kandel, R.; Haeffelin, M.; Pakhomov, L.; Golovko, V.; Mueller, J.; Stuhlmann, R. The ScaRaB Resurs earth radiation budget data set and first results. Bull. Am. Meteorol. Soc. 2001, 82, 1397-1408.

35. Roca, R.; Brogniez, H.; Chambon, P.; Chomette, O.; Cloché, S.; Gosset, M.; Mahfouf, J.-F.; Raberanto, P.; Viltard, N. The Megha-Tropiques mission: A review after three years in orbit. Front. Earth Sci. 2015, 3, 17. 
36. Suttles, J.; Green, R.; Minnis, P.; Smith, G.; Staylor, W.; Wielicki, B.; Walker, I.; Young, D.; Taylor, V.; Stowe, L. Angular Radiation Models for Earth-Atmosphere Systems, Vol. I Shortwave Radiation; NASA RP-1184; NASA Langley Research Center: Hampton, VA, USA, 1988.

37. Suttles, J.; Green, R.; Smith, G.; Wielicki, B.; Walker, I.; Taylor, V.; Stowe, L. Angular Radiation Models for Earth-Atmosphere Systems, Vol. II Longwave Radiation; NASA RP-1184; NASA Langley Research Center: Hampton, VA, USA, 1989.

38. Loeb, N.; Manalo-Smith, N.; Kato, S.; Miller, W.; Gupta, S.; Minnis, P.; Wielicki, B. Angular Distribution Models for Top-of-Atmosphere Radiative Flux Estimation from the Clouds and the Earth's Radiant Energy System Instrument on the Tropical Rainfall Measuring Mission Satellite. Part I: Methodology. J. Appl. Met. 2002, 42, 240-2659.

39. Harries, J.E.; Russell, J.E.; Hanafin, J.A.; Brindley, H.; Futyan, J.; Rufus, J.; Kellock, S.; Matthews, G.; Wrigley, R.; Last, A.; et al. The Geostationary Eareth Radiation Budget project. Bull. Am. Meteorol. Soc. 2005, 86, 945-960.

40. Schmetz, J.; Pili, P.; Tjemkes, S.; Just, D.; Kerkmann, J.; Rota, S.; Ratier, A. An introduction to Meteosat Second Generation. Bull. Am. Meteorol. Soc. 2002, 83, 977-992.

41. Dewitte, S.; Gonzalez, L.; Clerbaux, N.; Ipe, A.; Bertrand, C.; de Paepe, B. The geostationary Earth Radiation Budget Edition 1 data processing algorithms. Adv. Space Res. 2008, 41, 1906-1913.

42. Smith, G.L.; Szewczyck, P.; Rutan, D.; Lee, R. Comparison of measurements from satellite radiation budget instruments. J. Geophys. Res. Atmos. 2006, 111, D04101.

43. Clerbaux, N.; Russell, J.; Dewitte, S.; Bertrand, C.; Caprion, D.; de Paepe, B.; Gonzalez, L.; Ipe, A.; Bantges, R.; Brindley, H. Comparison of GERB instantaneous radiance and flux products with CERES Edition-2 data. Remote Sens. Environ. 2009, 113, 102-114.

44. Clerbaux, N.; Dewitte, S.; Ipe, A.; Baeck, P.-J.; Velazquez, A.; Decoster, I. Gerb/Ceres comparison update. In Proceedings of the Eumetsat Conference, Cordoba, Spain, 20-24 September 2010.

45. Chomette, O.; Capderou, M. CERES and ScaRaB comparison campaigns, method schedule for rendez-vous and results. In Proceedings of the Radiation Budget Workshop, Reading, UK, 18-21 October 2016.

46. Loeb, N.; Wielicki, B.; Doelling, D.; Smith, G.; Keyes, D.; Kato, S.; Manalo-Smith, N.; Wong, T. Towards optimal closure of the earth's top-of atmosphere radiation budget. J. Clim. 2009, 22, 748-766.

47. Trenberth, K.; Fasullo, J.; von Schuckmann, K.; Cheng, L. Insights into earth's energy imbalance from multiple sources. J. Clim. 2016, 29, 7495-7505.

48. Trenberth, K.; Caron, J. Estimates of meridional atmospheric and ocean heat transports. Bull. Am. Meteorol. Soc. 2001, 14, 3433-3443.

49. Stephens, G. Cloud feedbacks in the climate system: A critical review. J. Clim. 2005, 18-2, 237-273.

50. Charney, J. Dynamics of deserts and drought in the Sahel. Bull. Am. Meteorol. Soc. 1975, 101, 193-202.

51. Blake, D.; Krishnamurti, T.; Low-Nam, S.; Fein, J. Heat low over the Saudi Arabian desert during May 1979 (Summer MONEX). Mon. Weather Rev. 1983, 111, 1759-1775.

52. Phaden, M.M.; Zebiak, S.; Glanz, M. ENSO as an integrating concept in earth science. Science 2006, 314, 1740-1745.

53. Wolter, K.; Timlin, M. El Nino/Southern Oscillation behaviour since 1871 as diagnosed in an extended multivariate ENSO index (MEI.ext). Int. J. Climatol. 2011, 31, 1074-1087.

54. Hansen, J.; Ruedy, R.; Sato, M.; Lo, K. Global surface temperature change. Rev. Geophys. 2010, 48, RG4004. doi:10.1029/2010RG000345.

55. Wild, M. Global dimming and brightening: A review. J. Geophys. Res. Atmos. 2009, 114, D00D16, doi:10.1029/2008JD011470.

56. Dewitte, S.; Clerbaux, N.; Ipe, A.; Velazquez, A.; Baudrez, E.; Nevens, S.; Decoster, I. Climate monitoring with Earth Radiation Budget measurements. AIP Conf. Proc. 2013, 1531, 612-615. doi:10.1063/1.4804844.

57. Allan, R.; Liu, C.; Loeb, N.; Palmer, M.; Roberts, M.; Smith, D.; Vidale, P.-L. Changes in global net radiative imbalance 1985-2012. Geophys. Res. Lett. 2014, 41, 5588-5597. doi:10.1002/2014GL060962.

(C) 2017 by the authors. Licensee MDPI, Basel, Switzerland. This article is an open access article distributed under the terms and conditions of the Creative Commons Attribution (CC BY) license (http://creativecommons.org/licenses/by/4.0/). 